\title{
Percutaneous Tracheostomy in the Intensive Care Unit
}

\author{
Fatma Yıldırım', Yusuf Taha Güllü², Cengiz Bekir Demirel ${ }^{3}$ \\ ${ }^{1}$ Department of Chest Diseases, Gazi University Faculty of Medicine, Ankara \\ ${ }^{2}$ Department of Chest Diseases, Division of Intensive Care, Osmangazi University Faculty of Medicine, Eskişehir \\ ${ }^{3}$ Department of Anesthesiology and Reanimation, Gazi University Faculty of Medicine, Ankara
}

\begin{abstract}
Percutaneous tracheostomy (PT) has become an oftenly used procedure in critically ill patients requiring prolonged mechanical ventilation in recent years. The ideal timing and techniques of PT have been topics of considerable debate. In this review, we address general issues regarding PT (indications, contraindications, timing, preparation, techniques, complications) and specifically review the literatures regarding the comparison of techniques.
\end{abstract}

Keywords: Intensive care, percutaneous tracheostomy, techniques

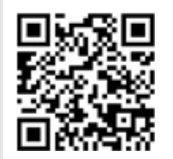

Received Date: 10.07.2014 Accepted Date: 06.11.2014 Available Online Date: 01.04 .2015 DOI: $10.5152 /$ ejp.2014.27247

Corresponding Author Fatma Ylldırım

E-mail: fatma_bodur2000@yahoo.com

- Available online at www.eurasianjpulmonol.com

(C) This work is licensed under a Creative (i) $\$$ Commons Attribution-NonCommercial
4.0 International License.

\section{INTRODUCTION}

Tracheostomy is one of the oldest surgical procedures, which was first used by Egyptians in 3600 B.C., and it requires the formation of an opening or ostium into the anterior wall of the trachea. While tracheostomy has been used as a life-saving procedure for the emergency treatment of upper airway obstruction for ages, Jackson brought a different surgical approach to tracheostomy and defined a standardized technique of systemic tracheostomy in 1909. He emphasized a long incision, a wide site, dividing the thyroid isthmus and avoiding the first and second tracheal rings (1). The control of diseases that can lead to airway obstruction through vaccination, development of antibiotics for upper airway infections, improvement of endotracheal intubation and bronchoscope reduced the need for tracheostomy. The emergency of tracheostomy has disappeared over time, and it has become an elective surgery in many cases. At the beginning of the $20^{\text {th }}$ century, tracheostomy began to be re-considered for patients with paralytic poliomyelitis who needed mechanical ventilation, and other methods were investigated as alternatives to surgical procedures. In 1943, tracheostomy was performed to remove bronchial secretions in a patient with bulbar poliomyelitis. The next step was to perform open percutaneous tracheostomy (PT) using the Seldinger guidewire technique. Ciaglia, a thoracic surgeon, successfully performed PT in 1985 and defined it as an elective bedside procedure that can be safely used $(2,3)$.

Percutaneous tracheostomy has recently become a frequently used procedure in the intensive care unit (ICU). In this review, PT indications, timing, techniques, and bronchoscopy and ultrasonography (USG) used for reducing complications in ICUs will be mentioned and an approach diagram will be established for ICU clinicians.

\section{Indications for Tracheostomy and Patient Selection for PT}

Patients who underwent endotracheal intubation in the ICU can be attached to a long-term mechanical ventilator. Prolonged endotracheal intubation causes some complications such as laryngeal injury, vocal cord paralysis, glottic and subglottic stenosis, infectious complications, and tracheal injury (tracheomalacia, tracheal dilatation, and tracheal stenosis). 
The aims of tracheostomy performed for reducing complications associated with prolonged endotracheal intubation are to decrease laryngeal damage, to facilitate nursing care and aspiration of respiratory tract, to improve patient's mobilization by providing safe airway, to make the transfer of a patient to the ICU easier, to increase the comfort of patient, to help patient's speech return early, and to facilitate oral feeding.

In addition to the maintenance of the airway in the ICU and prevention of intubation-related complications, tracheostomy has recently been frequently used for reducing the volume of dead space, decreasing airway resistance, and comforting patients during weaning from mechanical ventilation.

The indications for tracheostomy in the ICU are generally as follows (3-5):

- Failure to wean from mechanical ventilator (failed weaning)

- Patients needing long-term mechanical ventilation because of neurological diseases

- The cases in which adequate removal of bronchial secretions are required for providing airway patency

\section{Contraindications for PT}

The contraindications for PT are controversial, and various contraindications have been reported in different studies. Despite this, the contraindications for PT can be summarized as follows $(4,6-8)$ :

- Children (because of their small and mobile airway)

- Cases requiring urgent airway patency

- Anterior neck anatomical problems

$>$ Thyroid goiter or cervical innominate artery

$>$ Failure to palpate cricoid cartilage

$>$ Obesity or short neck

$>$ Spinal cord injury

- Previous tracheostomy application

- Severe thrombocytopenia and uncorrectable coagulopathy

- Inexperienced practitioner

However, it has been reported in many studies that PT can be safely performed in the presence of such contraindications. In spite of the low number of patients in the studies, there are some studies indicating that PT can be successfully performed in patients with short neck and obesity, in use of anti-platelet drugs use, liver diseases and cervical surgery (9-13).

\section{Timing of PT}

Although there are many studies conducted so far, the timing of tracheostomy in critical patients attached to a mechanical ventilator in the ICU still remains controversial. There is no consensus for the definition of early tracheostomy. The timing of tracheostomy varies from the $2^{\text {nd }}$ day to the $10^{\text {th }}$ day of mechanical ventilation.

In the prospective and randomized study conducted by Rumbak et al. (14) to compare early percutaneous dilatational tracheostomy (PDT) with prolonged intubation in intensive care patients, early tracheostomy was defined as PDT performed within $48 \mathrm{~h}$ after intubation, and delayed tracheostomy was defined as PDT performed between the $14^{\text {th }}$ and $16^{\text {th }}$ days after intubation. In this study, the mortality rate, pneumonia risk, and accidental extubation were found to be significantly lower in the early tracheostomy group than in the delayed tracheostomy group. Early tracheostomy reduced the duration of mechanical ventilation and ICU stay. Besides, the rates of oral and laryngeal injuries were higher in the group with prolonged intubation compared with the other group. In the retrospective cohort study of Scales et al. (15), early tracheostomy was defined as the tracheostomy performed until the $10^{\text {th }}$ day and delayed tracheostomy as the tracheostomy performed after the $10^{\text {th }}$ day. They found the 90-day and 1-year mortality rates to be lower in the early tracheostomy group than in the other group. On the other hand, Terragni et al. (16) conducted a randomized study with 419 patients and they compared early (6-8 days) and late (13-15 days) tracheostomy. Their study revealed earlier weaning from ventilation and shorter duration of ICU stay in the early tracheostomy group, but the effect of early tracheostomy on total hospital stay and survival rate was found to be insignificant. In another prospective randomized study conducted by Zheng et al. (17), 119 patients receiving prolonged mechanical ventilation in the ICU were evaluated. The patients participating in this study were divided into two groups: early (third day) and late $\left(15^{\text {th }}\right.$ day) tracheostomy groups. In the early tracheostomy group, compared with the other group, earlier weaning from mechanical ventilation, longer staying time without sedation, and earlier transfer from the ICU were observed. Moreover, pneumonia associated with ventilation was less frequently seen in these patients.

Although there are many studies showing the advantages of early tracheostomy, Young et al. (18) did not reveal the effect of early tracheostomy (within 4 days from admission) on mortality rate in patients undergoing mechanical ventilation in the ICU compared with the tracheostomy performed at least 10 days later. In this study, the use of a sedative was decreased after the application of tracheostomy, but a sedative was continued to be used in most patients. Moreover, it was detected that early tracheostomy did not provide a decrease in ventilatory support, did not reduce the duration of ICU and hospital stays, and did not make a difference in the use of antibiotics.

\section{Preparation for PT in the ICU}

\section{Patient Preparation}

The patient's suitability to tracheostomy should first be checked again. Pre-procedure preparation should be completed, and written informed consent should be obtained from the patient and/or family after giving necessary information. Coagulation parameters and general blood test results should be checked. Before the procedure, the patient should be prepared by giving sedatives, analgesics, and neuromuscular blockers. The mechanical ventilator should be switched to the control mode, and pre-oxygenation should be ensured with $100 \% \mathrm{FiO}_{2}$. The neck of the patient should be extended as much as possible by placing an elevator transversely under the shoulders (7). At this stage, the presence of any condition that can hinder the neck extension of the patient should be checked. Electrocautery and bronchoscope should be kept ready in case of bleeding. An adequate source of lighting is an essential component for tracheostomy. Furthermore, sterile gowns, gloves, caps, and masks for all personnel who will be involved in the procedure and adequate surgical sterilization should be provided.

\section{Identification of Anatomical Position}

The incision site is generally under 1 fingerbreadth from the cricothyroid membrane or above 1.5 or 2 fingerbreadths from the sternal notch. The incision should be made below the first and above the second tracheal rings or below the second and above the third tra- 
cheal rings (19). In this area, there were anterior jugular veins, which are risky structures for bleeding. These veins flow in the vertical direction. Therefore, vertical incision during PT can reduce the risk for bleeding.

\section{Preparation of Local Anesthesia and Equipment}

A solution of $2 \%$ lidocaine and noradrenaline is generally used for local anesthesia. Tracheostomy equipment should be checked before incision. The dilator or forceps that will be used in dilatation should be soaked with distilled water. The size of tracheostomy cannula should be checked to be proper for dilators, and it is lubricated with a lubricant gel (20).

\section{Incision and Dissection}

Although it is thought that vertical incision is better than horizontal incision, different results have been reported in studies. In the ICU, vertical incision is more frequently performed because of the less bleeding and easier traction.

\section{Tracheal Puncture}

The most important issue during PT is to perform a puncture into the trachea from the accurate point. After the incision is made, the operator can use a bronchoscope to control the place of needle, the direction of guidewire, and the location of tracheostomy. It is suggested that the use of a bronchoscope decreases the rate of complications such as pneumothorax, paratracheal localization, and posterior wall damage, and it is useful for the treatment of some complications such as endobronchial bleeding (21).

\section{Use of USG During Tracheal Puncture}

Lately, USG has been used for performing the tracheal puncture from the accurate point during PT and for reducing bleeding complications and the number of punctures. In the study by Yavuz et al. (22) who compared physical examination and USG findings of 341 cases, it was stated that the duration of the procedure is longer in patients undergoing USG-guided PT, but no difference is found with regard to perioperative complications. Furthermore, it was stated that the use of USG decreases the number of tracheal punctures and enables the procedure to be performed more safely and easily. In another study examining the use of USG during bronchoscope-guided PT, it was specified that USG increases the rate of midline tracheal puncture, decreases the number of tracheal punctures, and allows a tracheostomy cannula to be located between the targeted tracheal rings (23). In a study evaluating the use of USG during multiple dilatation method, no difference was found in terms of minor bleeding, needle puncture place, and the number of punctures when USG was used, even without a bronchoscope. The number of hypoxic episodes is lower, and the procedure time is shorter (24). Similarly, in the study conducted by Rudas et al. (25), when USG was used in the multiple dilatation method, the rate of entering into the trachea at the first puncture and the rate of accurate puncture increase but complications associated with the procedure do not.

\section{Protection of Airway During PT}

Protection of the airway during PT can be enabled with endotracheal tube (ET) or laryngeal mask (LMA). Strametz et al. (26) evaluated the use of ET and LMA in PT in their review, and they stated that the procedure time is shorter with LMA and that there is no difference between the two methods in terms of complications; however, no studies examining the long-term complications of LMA are available.

\section{PT Techniques}

Although many PT techniques have been defined so far, the most commonly used techniques are the PDT technique developed by Ciaglia et al. in 1985 and the percutaneous guide-wire dilatational tracheostomy technique developed by Griggs et al. in 1990. The essence of these methods is based on the insertion of a guide-wire following a puncture of the trachea (27).

\section{Multiple Dilatation Method (Ciaglia's Technique)}

The cuff of ET is withdrawn with the help of a laryngoscope or bronchoscope so that it is seen between the vocal cords. A 1-1.5 cm skin incision is made at the level of the second and third tracheal rings. The position of the needle is confirmed with the insertion of an injector with 2-3 $\mathrm{mL}$ physiological saline solution into the trachea in the midline and then with the aspiration of air.

A J-tipped guidewire is advanced through the needle, and the needle is then removed. A guiding catheter is placed on the guidewire. All dilatations are performed over this guidewire and guiding catheter combination. Dilatations are initiated with 12-F dilator and increased up to 36-F dilators for 8-mm tracheostomy cannula. The latest tracheostomy cannula with a fallen cuff is placed over the combination of guidewire and guiding catheter. The tracheostomy balloon is inflated (28).

\section{Single-Step Dilatation Technique (Ciaglia Blue Rhino)}

In order to reduce the duration of tracheostomy and complications such as posterior wall damage, bleeding, and hypoxia that can occur during multiple dilatations in the classical Ciaglia technique, a flexible, hydrophilic-coated rubber dilator was developed. This dilator called "Blue Rhino" is moistened with distilled water, and dilatation is performed over the guidewire and guiding catheter in a single step rather than in multiple steps in the typical Ciaglia technique (29).

\section{Forceps Dilatation Technique (Griggs)}

In this technique, a special pair of forceps, which was modified by Griggs et al. from Howard Kelly's forceps, is available in the reusable kit (30). At the tip of the forceps, there is a hole through which the guidewire can pass. This technique is the same as the Ciaglia method till the process of guidewire placement. The guidewire is passed through the hole at the tip of the forceps. Subcutaneous tissues and tracheal forceps are opened in one or two steps and dilated. When the stoma is large enough to place the cannula, the cannula is placed in the trachea and fixed (Figure 1).

\section{Fantoni's Translaryngeal Technique}

The main principle of this technique is slightly different from the other percutaneous methods. A rigid tracheoscope is first placed in the trachea. The tracheoscope, with a fiberoptic bronchoscope, is moved between the cartilage selected for tracheostomy. The position of the needle is determined through palpation of the tip of the tracheoscope or transillumination. The needle is constantly controlled and advanced for $2-3 \mathrm{~cm}$. A metal wire is advanced through the needle and tracheoscope toward the cranium and is removed out from the tip of the tracheoscope. Then, the tracheoscope and needle are removed, and a catheter is placed in the lower $1 / 3$ portion of the trachea. The ventilation of a patient is possible with this catheter. $A$ special tracheostomy cannula in the kit is placed over the wire. This cannula is withdrawn from the neck and removed outside from the trachea. A telescope is inserted from the tip of the cannula in the neck, and the cannula is rotated. In this way, the cannula is placed 

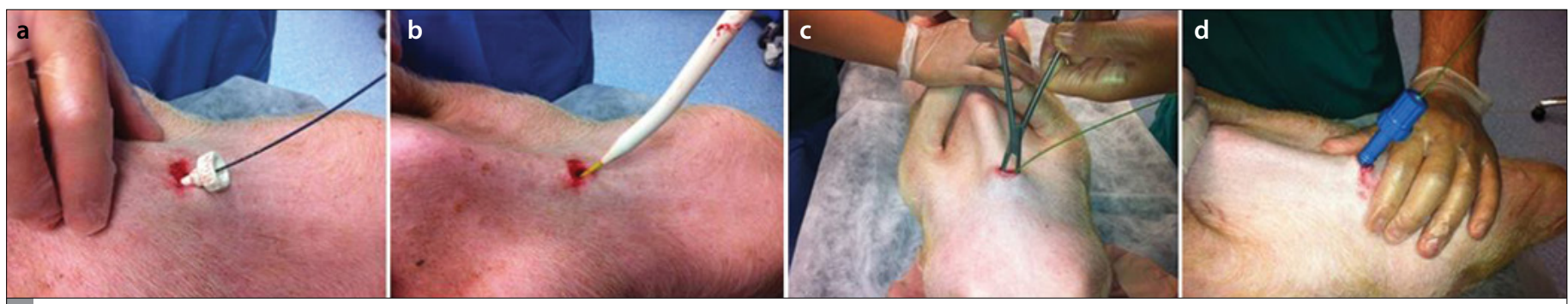

Figure 1.a-d. In the study comparing PT complications in swines, the insertion of the first dilator in the multiple dilatation technique (a); single-step dilatation technique (b); forceps dilatation technique (c); controlled-rotation technique (d) is observed

into the trachea in the appropriate position, and the cuff of the cannula is inflated $(31,32)$.

\section{Controlled-Rotating Dilatation Method (Percutwist)}

This is a newly developed method; a screw-like, hydrophilic-coated dilator, the coating of which is activated in water, is rotated clockwise on the guidewire in a controlled way, and pretracheal tissues can be dissected. After the widest part of the dilator is introduced into the trachea, the dilator is removed by reverse rotation. The tracheostomy tube can be placed over a guidewire similar to the previous methods (33).

\section{Complications of PT}

The main early complication of PT is bleeding on the anterior tracheal wall. It can be brought under control through pressure or a suture. Major bleeding is seen in less than $5 \%$ of cases, and it is typically venous. Catastrophic bleeding is rarely seen, and it is generally observed in the late period because of trachea-innominate artery fistula in many cases. Tracheo-innominate artery fistula is an uncommon yet life-threatening complication encountered during PT insertion. Its incidence rate is $0.3 \%$. Fatal aortic arcus laceration has been reported as an early complication of PT in one case. These complications should be determined in the early period; emergency neck exploration and appropriate surgical intervention should be performed (34-36).

In a multicenter study evaluating the early complications of tracheostomy, it was specified that postoperative bleeding is observed at a rate of $6.6 \%$ in PT and $1.9 \%$ in conventional surgical tracheostomy. In this study, it was also stated that flange tracheostomy tube sutures decrease bleeding in surgical tracheostomy (37).

Percutaneous tracheostomy can be performed with the guidance of USG in order to prevent pretracheal vascular structures. USG enables the neck anatomy to be understood better and helps the cannula of tracheostomy to be placed with a guide more safely. Preoperatively examining the vascular anatomy of the site can decrease the rate of bleeding by determining the locations of the structures such as inferior thyroid vein, high brachiocephalic vein, aberrant anterior jugular communicating vein, thyroid gland, and isthmus. The application of USG during the PT procedure is easy, and it can increase the accuracy and reliability of the procedure in patients with morbid obesity or cervical problems. However, no randomized controlled trial comparing standard PT and USG-guided PT procedures is available. USG-guided PT is not used routinely in many ICUs $(38,39)$.

It has been reported that most complications are encountered during the first year of PT application and especially in 20 cases of operator. Frequent complications caused by inexperienced practitioners in- clude emphysemas and tracheal mucosal ruptures. If dilators are kept too oblique because of the fear of posterior wall damage, the guidewire can be curved, and therefore, the pretracheal tissue can be extended. The insertion of a tracheostomy tube slowly can lead to emphysema. On the other hand, the too straight and sharp placement of needle or dilators can result in posterior wall injury. In some studies, the rate of posterior wall damage has been reported to range from $2 \%$ to $4 \%$ (40-42). Trottier et al. (43) stated the rate of posterior tracheal wall damage to be $29 \%$ in their study on PT. Nickells et al. (44) conducted a PT study with sheep and reported the presence of posterior wall damage in all the animals. Demirel et al. (45) compared multiple dilatation, single-step dilatation, forceps dilatation, and controlled-rotating PT techniques in their study and revealed that the duration of procedure was longer in multiple dilatation method compared with the other three methods, and they also found that there was no macroscopic and histopathological difference among the four techniques in terms of posterior tracheal wall damage. In the conclusion of their study, the use of bronchoscope in all PT techniques was suggested in order to reduce posterior tracheal wall damage.

\section{Comparison of PT Techniques}

In previous studies, conventional surgical techniques and one of the percutaneous techniques were compared. There are a few randomized controlled studies comparing the PT techniques with each other in terms of reliability and success rate. In the studies comparing the single-step dilatation and multiple dilatation PT techniques, it was stated that the duration of procedure is shorter in the single-step dilatation technique, whereas there is no difference with regard to the frequency of complications. One of these studies has suggested single-step dilatation technique to be the standard technique for PT because it is rapid. However, another study emphasized that it can lead to more fractures in tracheal rings because of it being a rapid method $(46,47)$. In the review by Sanabria (48) who examined the reliability of recent PT techniques, 14 randomized controlled trials were evaluated. No difference was found among the multiple dilatation, forceps dilatation, single-step dilatation, translaryngeal, and other PT techniques in terms of major bleeding. On the other hand, it was reported that bleeding is less observed in the single-step dilatation method and that it is easy to apply this technique and that clinicians are more experienced with this technique. Moreover, Kumar et al. (49) compared the forceps dilatation and single-step dilatation techniques in their prospective, randomized study that included a low number of patients. They found no difference between the two techniques in terms of major complications, duration of procedure, frequency of desaturation, hypercapnia, and increased peak pressure. In a similar study conducted by Karvandian et al. (50), it was stated that the forceps dilatation technique is more rapid and that skin incision is smaller in this technique, whereas complica- 
tions such as major bleeding and cardiac arrhythmia are less frequently seen in the single-step dilatation method. In the same study, it was noted that the use of single-step dilatation technique by less experienced clinicians would be safer. In a review evaluating the multiple dilatation, single-step dilatation, forceps dilatation, controlled-rotation, and Fantoni's translaryngeal and balloon dilatation PT techniques and comparing 33 studies, the forceps dilatation, multiple dilatation and single-step dilatation techniques are detected to be equal with regard to success rate and reliability. The single-step dilatation technique was found to have a lower rate of complication compared with the multiple dilatation technique, and the other three techniques were found to be less reliable and effective (22). In other studies where the multiple dilatation technique was compared with the other PT techniques, no difference was detected in terms of switching to surgery and major complications. In a study, it was specified that the multiple dilatation technique is more reliable. In another study, it was stated that the rate of mild complications is significantly higher in the multiple dilatation technique $(51,52)$.

The single-step dilatation technique seems to be the most frequently used PT technique. In a single-center prospective study evaluating the single-step dilatation method in $\mathbf{5 7 6}$ patients, the rate of failure, early complication of bleeding, and late-period complication were reported to be $0.5 \%, 3 \%$, and $0.7 \%$, respectively. In this study, death associated with the procedure in the early period was not observed, but death due to fistula in the late period was reported in two patients $(0.35 \%)(53,54)$.

Fantoni's translaryngeal technique is not a commonly used PT method in ICUs. Although the rate of complications does not differ in the studies conducted, it is not preferred because of the longer duration of the procedure and its high cost. However, because this method is internally controlled, it can be used in children or patients for whom it is difficult to determine the location of tracheostomy anatomically and in neurosurgical patients for whom intracranial pressure increase is very important $(55,56)$.

The use of the controlled-rotation technique is increasing in ICUs. This technique does not differ from other dilatational methods with regard to the frequency of complications. It is thought that this single-step dilatation (Ciaglia Blue Rhino) technique allows effective ventilation and reduces the risk for hypercapnia and intra-cranial pressure increase, and therefore, it can be used for patients with head injuries $(57,58)$.

\section{CONCLUSION}

The success of PT in the ICU is affected by many factors including the experience of the practitioner, general condition of patient, and neck anatomy. In order to reduce the complications, USG can be used for evaluating the anatomical structures of the neck before the procedure. On the other hand, a bronchoscope is used to confirm the location of tracheal puncture and to protect from posterior wall injuries. The timing and technique of tracheostomy should be decided based on the features of the patient and practitioner. However, the single-step dilatation technique seems to be the most successful and safest method among all the PT techniques.

Peer-review: Externally peer-reviewed.

Author contributions: Concept - F.Y.; Design - F.Y., Y.T.G.; Supervision - C.B.D.; Resource - F.Y., Y.T.G.; Materials - F.Y., Y.T.G.; Data Collection and/or Processing
- C.B.D.; Analysis and/or Interpretation - C.B.D.; Literature Search - F.Y., Y.T.G.; Writing - F.Y., Y.T.G.; Critical Reviews - C.B.D.

Conflict of Interest: No conflict of interest was declared by the authors.

Financial Disclosure: The authors declared that this study has received no financial support.

\section{REFERENCES}

1. Jackson C. Tracheostomy. Laryngoscope 1909; 19: 285-90. [CrossRef]

2. Ciaglia P, Firsching $R$, Syniec $C$. Elective percutaneous dilatational tracheostomy. A simple bedside procedure; preliminary report. Chest 1985; 87: 715-9. [CrossRef]

3. Borman J, Davidson JT. A history of tracheostomy: si spiritum ducit vivit (Cicero). Br J Anaesth 1963; 35: 388-90. [CrossRef]

4. Zeitouni AG, Kost KM. Tracheostomy: a retrospective review of 281 cases. J Otolaryngol 1994; 23: 61-6.

5. Kost KM. Endoscopic percutaneous dilatational tracheotomy: a prospective evaluation of 500 consecutive cases. Laryngoscope 2005; 115: 1-30. [CrossRef]

6. Zagli G, Linden M, Spina R, Bonizzoli M, Cianchi G, Anichini V, et al. Early tracheostomy in intensive care unit: a retrospective study of 506 cases of video-guided Ciaglia Blue Rhino tracheostomies. J Trauma 2010; 68: 367-72. [CrossRef]

7. Cho YJ. Percutaneous dilatational tracheostomy. Tuberc Respir Dis (Seoul) 2012; 72: 261-74. [CrossRef]

8. De Leyn P, Bedert L, Delcroix M, Depuydt P, Lauwers G, Sokolov Y, et al. Tracheotomy: clinical review and guidelines. Eur J Cardiothorac Surg 2007; 32: 412-21. [CrossRef]

9. Al-Ansari MA, Hijazi MH. Clinical review: percutaneous dilatational tracheostomy. Crit Care 2006; 10: 202. [CrossRef]

10. Tabaee A, Geng E, Lin J, Kakoullis S, McDonald B, Rodriguez H, et al. Impact of neck length on the safety of percutaneous and surgical tracheotomy: a prospective, randomized study. Laryngoscope 2005; 115: 1685-90. [CrossRef]

11. Romero CM, Cornejo RA, Ruiz MH, Gálvez LR, Llanos OP, Tobar EA, et al. Fiberoptic bronchoscopy-assisted percutaneous tracheostomy is safe in obese critically ill patients: a prospective and comparative study. J Crit Care 2009; 24: 494-500. [CrossRef]

12. Cabrini L, Bergonzi PC, Mamo D, Dedola E, Colombo S, Morero S, et al. Dilatative percutaneous tracheostomy during double antiplatelet therapy: two consecutive cases. Minerva Anestesiol 2008; 74: 565-7.

13. Auzinger G, O'Callaghan GP, Bernal W, Sizer E, Wendon JA. Percutaneous tracheostomy in patients with severe liver disease and a high incidence of refractory coagulopathy: a prospective trial. Crit Care 2007; 11: R110. [CrossRef]

14. Rumbak MJ, Newton M, Truncale T, Schwartz SW, Adams JW, Hazard PB. A prospective, randomized, study comparing early percutaneous dilational tracheotomy to prolonged translaryngeal intubation (delayed tracheotomy) in critically ill medical patients. Crit Care Med 2004; 32: 1689-94. [CrossRef]

15. Scales DC, Thiruchelvam D, Kiss A, Redelmeier DA. The effect of tracheostomy timing during critical illness on long-term survival. Crit Care Med 2008; 36: 2547-57. [CrossRef]

16. Terragni $P P$, Antonelli $M$, Fumagalli R, Faggiano C, Berardino M, Pallavicini $\mathrm{FB}$, et al. Early vs late tracheotomy for prevention of pneumonia in mechanically ventilated adult ICU patients: a randomized controlled trial. JAMA 2010; 303: 1483-9. [CrossRef]

17. Zheng Y, Sui F, Chen XK, Zhang GC, Wang XW, Zhao S, et al. Early versus late percutaneous dilational tracheostomy in critically ill patients anticipated requiring prolonged mechanical ventilation. Chin Med J (Engl) 2012; 125: 1925-30.

18. Young D, Harrison DA, Cuthbertson BH, Rowan K; TracMan Collaborators. Effect of early vs late tracheostomy placement on survival in patients receiving mechanical ventilation: the TracMan randomized trial. JAMA 2013; 309: 2121-9. [CrossRef] 
19. De Leyn $P$, Bedert L, Delcroix M, Depuydt P, Lauwers $G$, Sokolov $Y$, et al. Tracheotomy: clinical review and guidelines. Eur J Cardiothorac Surg 2007; 32: 412-21. [CrossRef]

20. Susarla SM, Peacock ZS, Alam HB. Percutaneous dilatational tracheostomy: review of technique and evidence for its use. J Oral Maxillofac Surg 2012; 70: 74-82. [CrossRef]

21. Álvarez-Maldonado P, Pérez-Rosales A, Núnez-Pérez Redondo C, Cueto-Robledo G, Navarro-Reynoso F, Cicero-Sabido R. Bronchoscopy-guided percutaneous tracheostomy. A safe technique in intensive care. Cir Cir 2013; 81: 93-7.

22. Yavuz A, Yılmaz M, Göya C, Alimoglu E, Kabaalioglu A. Advantages of US in Percutaneous Dilatational Tracheostomy: Randomized Controlled Trial and Review of the Literature. Radiology 2014; 273:927-36. [CrossRef]

23. Dinh VA, Farshidpanah S, Lu S, Stokes P, Chrissian A, Shah H, et al. Real-time sonographically guided percutaneous dilatational tracheostomy using a long-axis approach compared to the landmark technique. J Ultrasound Med 2014; 33: 1407-15. [CrossRef]

24. Chacko J, Brar G, Kumar U, Mundlapudi B. Real-time ultrasound guided percutaneous dilatational tracheostomy -with and without bronchoscopic control: an observational study. Minerva Anestesiol 2014 Jul 24.

25. Rudas M, Seppelt I, Herkes R, Hislop R, Rajbhandari D, Weisbrodt L. Traditional landmark versus ultrasound guided tracheal puncture during percutaneous dilatational tracheostomy in adult intensive care patients: a randomised controlled trial. Crit Care 2014; 18: 514. [CrossRef]

26. Strametz R, Pachler C, Kramer JF, Byhahn C, Siebenhofer A, Weberschock T. Laryngeal mask airway versus endotracheal tube for percutaneous dilatational tracheostomy in critically ill adult patients. Cochrane Database Syst Rev 2014; 6: CD009901. [CrossRef]

27. Cabrini L, Monti G, Landoni G, Biondi-Zoccai G, Boroli F, Mamo D, et al. Percutaneous tracheostomy, a systematic review. Acta Anaesthesiol Scand 2012; 56: 270-81. [CrossRef]

28. Walz MK, Peitgen K, Thürauf N, Trost HA, Wolfhard U, Sander A, et al. Percutaneous dilatational tracheostomy-early results and long-term outcome of 326 critically ill patients. Intensive Care Med 1998; 24: 685-90. [CrossRef]

29. Byhahn C, Lischke V, Halbig S, Scheifler G, Westphal K. Ciaglia blue rhino: a modified technique for percutaneous dilatation tracheostomy. Technique and early clinical results. Anaesthesist 2000; 49: 202-6. [CrossRef]

30. Sheu CC, Tsai JR, Hung JY, Cheng MH, Chong IW, Hwang JJ, et al. A simple modification of Ciaglia Blue Rhino technique for tracheostomy: using a guidewire dilating forceps for initial dilation. Eur J Cardiothorac Surg 2007; 31: 114-9. [CrossRef]

31. Fantoni A, Ripamonti D. A non-derivative, non-surgical tracheostomy: the translaryngeal method. Intensive Care Med 1997; 23: 386-92. [CrossRef]

32. Fantoni A, Ripamonti D. Tracheostomy in pediatrics patients. Minerva Anestesiol 2002; 68: 433-42.

33. Yurtseven N, Aydemir B, Karaca P, Aksoy T, Komurcu G, Kurt M, et al. PercuTwist: a new alternative to Griggs and Ciaglia's techniques. Eur J Anaesthesiol 2007; 24: 492-7. [CrossRef]

34. Shlugman D, Satya-Krishna R, Loh L. Acute fatal haemorrhage during percutaneous dilatational tracheostomy. Br J Anaesth 2003; 90: 517-20. [CrossRef]

35. El Solh AA, Jaafar W. A comparative study of the complications of surgical tracheostomy in morbidly obese critically ill patients. Crit Care 2007; 11: R3. [CrossRef]

36. Ayoub OM, Griffiths MV. Aortic arch laceration: A lethal complication after percutaneous tracheostomy. Laryngoscope 2007; 117: 176-8. [CrossRef]

37. Halum SL, Ting JY, Plowman EK, Belafsky PC, Harbarger CF, Postma GN, et al. A multi-institutional analysis of tracheotomy complications. Laryngoscope 2012; 122: 38-45. [CrossRef]

38. Muhammad JK, Major E, Patton DW. Evaluating the neck for percutaneous dilatational tracheostomy. J Craniomaxillofac Surg 2000; 28: 336-42. [CrossRef]
39. Rajajee V, Fletcher JJ, Rochlen LR, Jacobs TL. Real-time ultrasound-guided percutaneous dilatational tracheostomy: a feasibility study. Crit Care 2011; 15: R67. [CrossRef]

40. Petros S, Engelmann L. Percutaneous dilatational tracheostomy in a medical ICU. Intensive Care Med 1997; 23: 630-4. [CrossRef]

41. Massick DD, Yao S, Powell DM, Griesen D, Hobgood T, Allen JN, et al. Bedside tracheostomy in the intensive care unit: a prospective randomized trial comparing open surgical tracheostomy with endoscopically guided percutaneous dilational tracheotomy. Laryngoscope 2001; 111:494-500. [CrossRef]

42. Fernandez L, Norwood S, Roettger R, Gass D, Wilkins H 3rd. Bedside percutaneous tracheostomy with bronchoscopic guidance in critically ill patients. Arch Surg 1996; 131: 129-32. [CrossRef]

43. Trottier SJ, Hazard PB, Sakabu SA, Levine JH, Troop BR, Thompson JA, et al. Posterior tracheal wall perforation during percutaneous dilational tracheostomy: an investigation into its mechanism and prevention. Chest 1999; 115: 1383-9. [CrossRef]

44. Nickells JS, Dahlstrom JE, Bidstrup H, Dobbinson TL. Acute tracheal trauma in sheep caused by percutaneous tracheostomy. Anaesth Intensive Care 2002; 30: 619-23.

45. Demirel CB, Haltaş H, Pampal HK, Ünal Y, Işık B, Uysal M. Comparison of the effects of different percutaneous tracheotomy techniques on acute tracheal trauma. Turk J Med Sci 2014; 44: 68-72. [CrossRef]

46. Johnson JL, Cheatham ML, Sagraves SG, Block EF, Nelson LD. Percutaneous dilational tracheostomy: a comparison of single- versus multiple-dilator techniques. Crit Care Med 2001; 29: 1251-4. [CrossRef]

47. Byhahn C, Wilke HJ, Halbig S, Lischke V, Westphal K. Percutaneous tracheostomy: ciaglia blue rhino versus the basic ciaglia technique of percutaneous dilational tracheostomy. Anesth Analg 2000; 91: 882-6. [CrossRef]

48. Sanabria A. Which percutaneous tracheostomy method is better? A systematic review. Respir Care 2014; 59: 1660-70. [CrossRef]

49. Kumar M, Trikha A, Chandralekha. Percutaneous dilatational tracheostomy: Griggs guide wire dilating forceps technique versus ULTRA-perc single-stage dilator - A prospective randomized study. Indian J Crit Care Med 2012; 16: 87-92. [CrossRef]

50. Karvandian K, Yousefian M, Khan ZH, Baigmohammadi T, Shabani S. Comparative clinical trial between Ciaglia and Griggs techniques during tracheostomy performed in patients admitted to intensive care unit. Acta Med Iran 2012; 50: 525-9.

51. Van Heurn LW, Mastboom WB, Scheeren Cl, Brink PR, Ramsay G. Comparative clinical trial of progressive dilatational and forceps dilatational tracheostomy. Intensive Care Med 2001; 27: 292-5. [CrossRef]

52. Kaiser E, Cantais E, Goutorbe P, Salinier L, Palmier B. Prospective randomized comparison of progressive dilational vs forceps dilational percutaneous tracheostomy. Anaesth Intensive Care 2006; 34: 51-4.

53. De Leyn P, Bedert L, Delcroix M, Depuydt P, Lauwers G, Sokolov Y, et al; Belgian Association of Pneumology and Belgian Association of Cardiothoracic Surgery. Tracheotomy: clinical review and guidelines. Eur J Cardiothorac Surg 2007; 32: 412-21. [CrossRef]

54. Dempsey GA, Grant CA, Jones TM. Percutaneous tracheostomy: a $6 \mathrm{yr}$ prospective evaluation of the single tapered dilator technique. Br J Anaesth 2010; 105: 782-8. [CrossRef]

55. Divisi D, Altamura G, Di Tommaso S, Di Leonardo G, Rosa E, De Sanctis C, et al. Fantoni translaryngeal tracheostomy versus ciaglia blue rhino percutaneous tracheostomy: a retrospective comparison. Surg Today 2009; 39: 387-92. [CrossRef]

56. Carrer S, Basilico S, Rossi S, Bosu A, Bernorio S, Vaghi GM. Outcomes of percutaneous tracheostomy. Minerva Anestesiol 2009; 75: 607-15.

57. Montcriol A, Bordes J, Asencio Y, Prunet B, Lacroix G, Meaudre E. Bedside percutaneous tracheostomy: a prospective randomised comparison of PercuTwist versus Griggs' forceps dilational tracheostomy. Anaesth Intensive Care 2011; 39: 209-16.

58. Imperiale C, Magni G, Favaro R, Rosa G. Intracranial pressure monitoring during percutaneous tracheostomy "percutwist" in critically ill neurosurgery patients. Anesth Analg 2009; 108: 588-92. [CrossRef] 